\title{
ANALISIS TEKANAN COBLOS BAN TUBETYPE
}

\author{
Sufiya Putri Martina ${ }^{1,2, a)}$, Sulhadi ${ }^{1}$, Mahardika Prasetya Aji ${ }^{1}$ \\ ${ }^{1}$ Program Pasca Sarjana Pendidikan Fisika UNNES \\ Kampus UNNES Bendan Ngisor Semarang 50233 \\ ${ }^{2}$ SMK Sudirman Semarang \\ Email : a)sofiamartina.sm@gmail.com
}

\begin{abstract}
Abstrak
Ban adalah bagian penting dari sebuah kendaraan bermotor karena ban satu-satunya bagian dari kendaraan bermotor yang mempunyai kontak langsung dengan jalan. Paku mempunyai bagian yang runcing pada ujungnya. Sehingga ketika mendapatkan sebuah tekanan, paku akan mampu menembus ban atau mencoblos ban. Tekanan coblos setiap ban memiliki nilai yang berbeda karena adanya variasi diameter paku $1,25 \mathrm{~mm}, 1,55 \mathrm{~mm}, 1,65 \mathrm{~mm}, 1,85 \mathrm{~mm}, 2,05 \mathrm{~mm}$, dan $2,8 \mathrm{~mm}$. Pengambilan data menggunakan compressive strength. Hasil penelitiannya yaitu dengan diameter terbesar $2,8 \mathrm{~mm}$ dapat mencoblos ban dengan tekanan yang besar $10 \times 10^{4}$ Joule. Sedangkan untuk diameter yang paling kecil $1,25 \mathrm{~mm}$ dapat mencoblos ban dengan tekanan $40 \times 10^{3}$ Joule. Sehingga dari hasil tersebut dapat disimpulkan bahwa setiap paku yang memiliki diameter yang berbeda mempunyai tekanan coblos yang berbeda untuk menembus ban.
\end{abstract}

Kata-kata kunci : Ban Tubetype, Compressive Strength

Abstract

Tire is the most important part of a motor vehicle because the tires only part of a motor vehicle who have direct contact with the road. Has the sharpened spikes on the ends. So when getting a pressure , a nail will be able to penetrate the tire or tires voting . Penetration pressure of each tire has a different value because of variations in the diameter of the nail $1,25 \mathrm{~mm}, 1,55 \mathrm{~mm}, 1,65 \mathrm{~mm}, 1,85 \mathrm{~mm}$, $2,05 \mathrm{~mm}$ and $2,8 \mathrm{~mm}$. Retrieving data using compressive strength. The results of his research is the largest diameter $2,8 \mathrm{~mm}$ can cast their huge tires with the pressure of $10 \times 10^{4}$ Joules. While for most small diameter $1,25 \mathrm{~mm}$ can cast their tires with a pressure of $40 \times 10^{3}$ Joule. So, from these results it can be concluded that any spikes that have different diameters have different pressure to penetrate the tire

Keywords : Tubetype tire, Compressive Strength

\section{Pendahuluan}

Setiap kendaraan yang diciptakan terdiri berbagai macam komponen yang mempunyai fungsi dan tugas masing-masing. Salah satu komponen dalam kendaraan adalah ban. Ban merupakan bagian dari roda kendaraan yang bersentuhan langsung dengan permukaan jalan. Beban ban sangat berat karena sebagai tumpuan berat kendaraan dan muatannya. Membuat peranan ban sangat penting mengingat fungsi dan kerjanya menyangga beban keseluruhan pada kendaraan, baik beban kosong maupun beban penuh/maksimal [1]. Ban saat ini memiliki dua jenis yaitu ban tubeless dan ban tubetype yang biasa disebut dengan ban biasa. Ban tubetype atau disebut ban biasa adalah ban jenis konvensional yang masih memakai ban dalam. Meskipun ada juga ban jenis tubeless juga menggunakan ban dalam tetapi ban jenis tubetype ini lebih lemah dalam menghadapi benda tajam karena strukturnnya yang tidak sekeras ban tubeless sehingga lebih mudah bocor [2]. Banyak penyebab dari kebocoran suatu ban salah satunya adalah tercoblosnya ban oleh paku. Paku mempunyai bagian yang runcing pada ujungnya. Sehingga ketika mendapatkan sebuah tekanan, paku akan mampu menembus ban atau mampu mencoblos ban. Dikatakan mendapatkan sebuah tekanan karena ada gaya yang bekerja pada ban [4]. Kita ketahui bahwa banyak jenis dan variasi ukuran paku serta memiliki diameter yang berbeda-beda. Salah satu jenis paku adalah paku kayu. Paku kayu mempunyai ukuran yang berbeda, dari ukuran kecil sampai ukuran besar dan masingmasing paku dibedakan atas panjang dan juga diameter paku. Karena adanya variasi ukuran paku, tekanan untuk mencoblos ban tersebut juga berbeda. Semakin runcing paku maka hanya dengan tekanan kecil paku sudah dapat tercoblos hingga menembus ban. Berbeda dengan paku ukuran besar yang mungkin tidak seruncingpaku 
kecil, maka paku tersebut membutuhkan tekanan yang besar untuk mencoblos ban.

Tekanan menurut sistematis dalam fisika merupakan gaya dibagi dengan persatuan luas. Pernyataan secara teoritis dalam sebuah tekanan adalah besarnya tekanan pada suatu luas daerah tertentu tergantung dari besarnya gaya yang diberikan. Semakin besar gaya yang diberikan, semakin besar tekanan yang dihasilkan. Sebaliknya, semakin kecil gaya yang diberikan, maka akan semakin kecil pula tekanan yang dihasilkan. Luas permukaan yang mengalami tekanan juga ikut menentukan besarnya tekanan yang dihasilkan. Semakin besar luas permukaan yang mengalami tekanan, maka akan semakin kecil tekanan yang dihasilkan. Sebaliknya, jika luas permukaan yang mengalami tekanan semakin kecil, maka tekanan yang dihasilkan akan semakin besar [3].

Sifat-sifat mekanik zat padat seperti kekuatan Tarik (tensile strength), kekuatan tekan (compressive strength), modulus elastisitas $\mathrm{M}$ (modulus young,modulus geser dan modulus bulk), keuletan, ketangguhan, kekerasan, dan kekuatan impak merupakan sifat-sifat fisis zat padat yang perlu mendapatkan perhatian bagi para peneliti yang melakukan rekayasa bahan karena sifat-sifat ini memberikan peranan penting bagi terciptanya suatu bahan yang sesuai dengan yang dikehendaki. Mengingat pentingnya pengetahuan tentang sifat-sifat mekanik dalam rekayasa bahan, maka akan dilakukan pengukuran tekanan menggunakan alat compressive strength [5]. Sifatsifat mekanik yang akan diukur adalah kekuatan tekan dari sebuah paku untuk mengetahui tekanan yang mampu menembus ban.

\section{Metodologi Penelitian}

A. Alat yang digunakan dalam penelitian :
1) Compressive Strength

B. Bahan yang digunakan :
1) Ban Tubetype
2) Paku

C. Prosedur Penelitian

Proses pengujian kuat tekan daya coblos ban menggunakan alat Compressive Strength:

1) Menyiapkan ban tubetype dan paku yang akan diuji.

2) Melakukan pengukuran diameter pada paku agar pengujian lebih mudah dilakukan.

3) Meletakkan ban pada alat uji compressive strength.

4) Melakukan pengujian dengan menjalankan mesin uji hingga hasil uji terbaca pada alat.

5) Melakukan pembebasan sampai beban maksimum.

6) Membaca dan mencatat hasil uji untuk dianalisis.
Dari proses pengujian, data yang diperoleh berupa besarnya sebuah massa yang akan digunakan untuk menentukan gaya dengan dikalikan dengan percepatan gravitasi. Sehingga dari gaya tekan tersebut, akan didapatkan besarnya tekanan sebuah paku yang mencoblos ban.

\section{Hasil dan Pembahasan}

Penelitian yang dilakukan tentang tekanan coblos pada paku yang mampu menembus ban dengan memvariasikan diameter paku. Prosedur penelitian yang pertama dilakukan dengan pengujian menggunakan alat compressive strength. Pada gambar 1 menunjukkan alat compressive strength

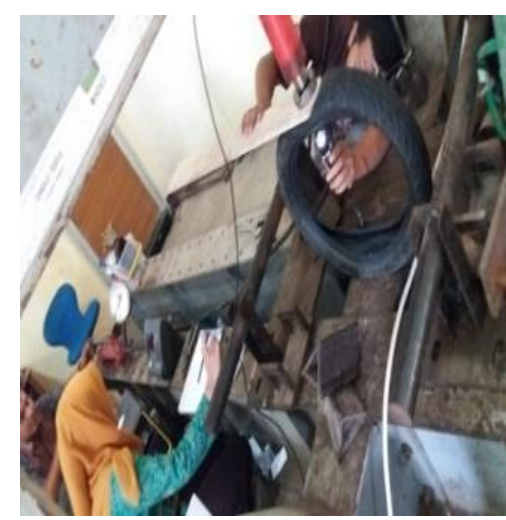

Gambar 1. Alat Compressive Strength 1

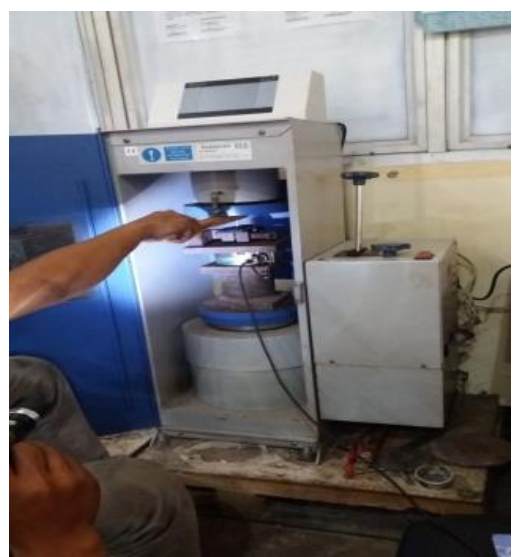

Gambar 2. Alat Compressive Strength 2

Alat tersebut digunakan untuk mengetahui nilai massa yang diberikan untuk paku agar mampu menembus ban. Nilai massa tersebut dapat menunjukkan gaya dan tekanan yang diberikan pada paku. 
Tabel 1. Hasil uji alat Compressive Strength

\begin{tabular}{|c|c|c|}
\hline $\begin{array}{c}\text { Diameter } \\
\text { Paku }(\mathrm{mm})\end{array}$ & $\begin{array}{c}\text { Nilai massa } \\
\text { tekan }(\mathrm{kg})\end{array}$ & $\begin{array}{c}\text { Nilai gaya } \\
\text { tekan }(\mathrm{N})\end{array}$ \\
\hline 1,25 & 5 & 50 \\
\hline 1,55 & 5 & 50 \\
\hline 1,65 & 5 & 50 \\
\hline 1,85 & 10 & 100 \\
\hline 2,05 & 15 & 150 \\
\hline 2,80 & 17,5 & 175 \\
\hline
\end{tabular}

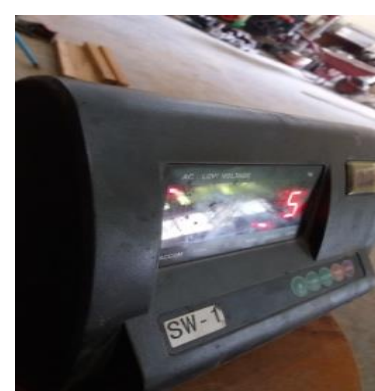

Gambar 3. Hasil alat Compressive Strength

Dalam pengambilan data, dilakukan sebanyak tiga kali sampel untuk setiap diameter paku. Dari ketiga sampel akan dirata-rata dan diambil satu nilai massa. Gaya tekan diperoleh menggunakan formula:

$$
F=m \cdot g
$$

Dengan m sebagai massa yang diperoleh melalui alat compressive strength dan $\mathrm{g}$ merupakan nilai percepatan gravitasi $10 \mathrm{~m} / \mathrm{s}^{2}$. Setelah didapatkan nilai gaya tekan selanjutnya mencari tekanan untuk masing-masing diameter.

Pada Tabel 2 menyatakan nilai tekanan dengan formula:

$$
P=\frac{F}{A}
$$

F menyatakan sebagai gaya tekan dan A merupakan luas penampang yang diperoleh dari diameter paku. Berdasarkan hasil tersebut diperoleh nilai tekanan yang berbeda sesuai dengan diameter masing-masing paku. Dengan diameter paku yang terkecil $1,25 \mathrm{~mm}$ mendapat tekanan lebih kecil yaitu $40 \times 10^{3} \mathrm{~J}$ dan diameter yang terbesar $2,8 \mathrm{~mm}$ mendapatkan nilai tekanan yang besar yaitu $10 \times 10^{4} \mathrm{~J}$.

Tabel 2. Hasil Tekanan Coblos

\begin{tabular}{|c|c|c|}
\hline $\begin{array}{c}\text { Diameter } \\
\text { Paku (mm) }\end{array}$ & $\begin{array}{c}\text { Gaya tekan } \\
(\mathrm{N})\end{array}$ & $\begin{array}{c}\text { Tekanan Coblos } \\
(\mathrm{J})\end{array}$ \\
\hline 1,25 & 50 & $40 \times 10^{3}$ \\
\hline 1,55 & 50 & $32 \times 10^{3}$ \\
\hline 1,65 & 50 & $30 \times 10^{3}$ \\
\hline 1,85 & 100 & $54 \times 10^{3}$ \\
\hline 2,05 & 150 & $73 \times 10^{3}$ \\
\hline 2,8 & 175 & $10 \times 10^{4}$ \\
\hline
\end{tabular}

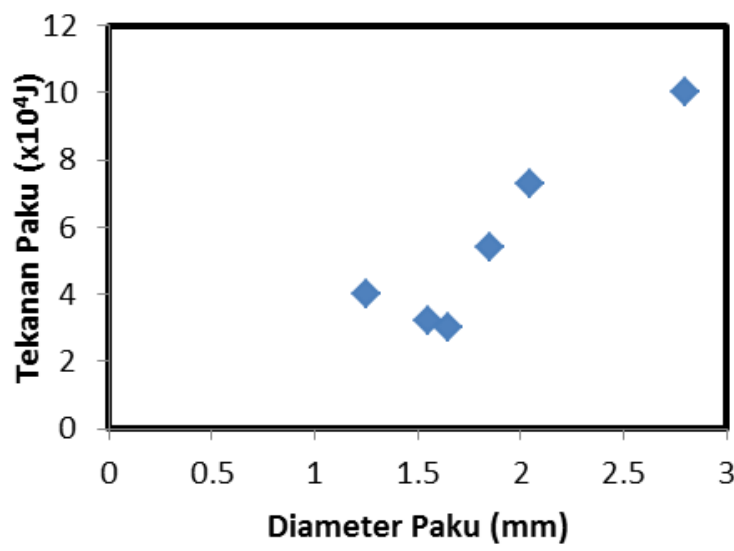

Gambar 4.Grafik diameter paku terhadap tekanan coblos ban

Artinya dengan massa $5 \mathrm{~kg}$ sudah mampu memberikan tekanan yang dapat menembus ban. Sedangkan, untuk paku dengan diameter $2,8 \mathrm{~mm}$ membutuhkan massa sebesar $20 \mathrm{~kg}$. Hal ini dapat membuktikan jika massa kurang dari $5 \mathrm{~kg}$, untuk diameter $1,25 \mathrm{~mm}$ tidak menyebabkan kebocoran karena paku tidak mampu menembus ban hingga dalam. Begitu juga dengan diameter $2,8 \mathrm{~mm}$, jika massaanya kurang dari $20 \mathrm{~kg}$ tidak menyebabkan kebocoran pada ban.

\section{Simpulan}

Dari data yang telah diperoleh dapat disimpulkan bahwa bahwa setiap paku yang memiliki diameter yang berbeda dan mempunyai tekanan coblos yang berbeda. Hal ini dapat dibuktikan melalui data yang telah diperoleh bahwa diameter paku $1,25 \mathrm{~mm}$ dapat mencoblos ban dengan tekanan $40 \times 10^{3}$ Joule dan diameter paku $2,8 \mathrm{~mm}$ dapat mencoblos ban dengan tekanan 10x10 $0^{4}$ Joule sesuai dengan tabel 1 dan 2 .

\section{Ucapan Terimakasih}

Terimakasih untuk semua pihak yang telah membantu dalam penelitian ini. Pengelola laboratorium dan semua pihak yang telah turut andil dalam penelitian ini.

\section{Daftar Acuan}

[1] Wahyu, Hidayat. Modifikasi Ban Motif Alur Rib Segitiga Untuk Meningkatkan Keselamatan Berkendara Sepeda Motor. Program Studi Teknik Mesin Fakultas Teknik. UNISMA, Bekasi. Vol 11, No 012010

[2] Aini, Nur. Komponen Ban dalam Kendaraan Otomotif. Fakultas Teknik. Universitas Indonesia, Depok. 2012 
[3] Ettylist. Tekanan. https://ettylist.wordpress.com /2014/01/09/tekanan/. 2014. (Diakses 4 Februari 2016).

[4] Poniran. Macam-macam bocor pada ban dan penyebabnya.http://www.dukunban.ga/2015/0 9/macam-macam-bocor-pada-ban-dalam-dan- penyebabnya.html. 2015. (Diakses 24 Januari 2016)

[5] Moh. Saad Baruqi,dkk. Pengaruh Tensile Strength, Compressive Strength dan Modulus Elastisitas Benda Padat. Jurusan Fisika Fakultas Sains dan Teknologi. Universitas Airlangga, Surabaya. 2015 